\title{
A Weight-Loss and Healthy Living Program for Men Delivered in Swedish Football and Ice-Hockey Clubs (ViSiT): Results from the ViSiT Feasibility Study
}

\author{
Matti Leijon 1, Katarina Åsberg1, Nadine Karlsson'1, Janna Skagerström¹, Petra Dannapfel1, \\ Daniel Arvidsson ${ }^{2}$ \\ ${ }^{1}$ Department of Medical and Health Sciences, Linköping University, Linköping, Sweden \\ ${ }^{2}$ Center for Health and Performance, Department of Food and Nutrition and Sport Science, University of Gothenburg, \\ Gothenburg, Sweden \\ Email: ^matti.leijon@regionostergotland.se
}

How to cite this paper: Leijon, M., Åsberg, K., Karlsson, N., Skagerström, J., Dannapfel, P. and Arvidsson, D. (2019) A Weight-Loss and Healthy Living Program for Men Delivered in Swedish Football and Ice-Hockey Clubs (ViSiT): Results from the ViSiT Feasibility Study. Health, 11, 1473-1486.

https://doi.org/10.4236/health.2019.1110110

Received: September 19, 2019

Accepted: October 28, 2019

Published: October 31, 2019

Copyright $\odot 2019$ by author(s) and Scientific Research Publishing Inc. This work is licensed under the Creative Commons Attribution International License (CC BY 4.0).

http://creativecommons.org/licenses/by/4.0/ Open Access

\begin{abstract}
Background: Men appear less interested than women in engaging in healthpromoting programs. We investigated the feasibility and proof of concept of a novel intervention program targeting male supporters of professional sports clubs. Methods: Our intervention is called ViSiT and the target population in this study was overweight male supporters aged 35 - 65 years with a body mass index $\geq 28 \mathrm{~kg} / \mathrm{m}^{2}$, recruited through one football and one ice-hockey club. The participants $(n=22)$ participated in a 12-week lifestyle intervention with a 52-week follow-up. Body fat was assessed using bioelectrical impedance analysis. Results: The retention rate was high with 21 participants completing the 12-week program and 17 attending at least 10 of 12 sessions. Mean (standard deviation) body weight and fat reduction after 12 weeks was 8.2 (4.6) $\mathrm{kg}$ and 6.6 (3.6) $\mathrm{kg}$, respectively. At 52 weeks, body weight and fat reduction were maintained at $6.4(6.7) \mathrm{kg}$ and $4.5(6.5) \mathrm{kg}$. Even after 52 weeks follow-up, the participants appreciated most components of the ViSiT program and perceived the ViSiT program to have high impact on most health-related aspects investigated. Conclusions: The ViSiT program demonstrated a successful retention rate and clinically relevant weight reduction in Swedish overweight men. The maintenance of bodyweight reduction and positive experience after 1 year indicate a long-term effect of the ViSiT concept.
\end{abstract}

\section{Keywords}

Public Health, Overweight, Weight-Loss, Physical Activity, Lifestyle, Fans 


\section{Background}

Obesity is a major public health concern. Globally, $39 \%$ of adults are overweight and 13\% are obese and these rates have more than doubled since 1980 [1]. The prevalence of obesity is estimated to double again in the next 15 years [2]. Obesity contributes to increased risk of all-cause mortality worldwide, with a higher risk in men compared with women [3]. In Sweden, $58 \%$ of men and $45 \%$ of women (16 - 84 years) were overweight or obese (body mass index [BMI] $>25$ $\left.\mathrm{kg} / \mathrm{m}^{2}\right)$ in 2018, and the prevalence is increasing in most age groups [4].

Weight-loss interventions for obese adults decrease all-cause mortality by six fewer deaths per 1000 participants [5]. However, it has been noted that men are often unwilling and lack the motivation to engage with health-related information [6]. Moreover, men are underrepresented in weight-loss intervention studies both with regard to the number of studies presented and the number of participants recruited [7] and seem to be underrepresented in both commercial and state-delivered weight-loss initiatives and in weight-loss research more generally [8]. With regard to group-based interventions, men-only groups are almost seven times less common than women-only groups, although the men-only interventions are twice as effective [9]. Group-based interventions are effective for weight reduction with lower costs of delivery, especially men-only groups that promote high retention and commitment to the weight-reduction program [8] [9]. Intervention programs are more successful if diet and physical activity are targeted together and include behavior change techniques [8] [10]. The obesity-related risk of disease can be lowered with as little as $5 \%$ loss of body weight [11]. Further, group-based interventions targeting diet and/or physical activity can generate clinically meaningful weight loss up to 24 months [9].

Sport arenas are good locations for gathering people, including those with a low level of education and low health literacy, who are difficult to reach with health interventions and education [12]. Professional sports settings have the potential to engage hard-to-reach populations in health improvement programs, but previous studies show that delivery refinements are needed to support adoption by men [13]. In addition, it is important that adequate support and opportunities are made available when information on weight and disease risk is fed back to the participants within the context of behavior change programs [14].

A gender-sensitive lifestyle program, football fans in training (FFIT), delivered in professional football clubs, has shown great promise in Scotland and could play an important public health role in engaging underserved men. FFIT aims to recruit overweight supporters of professional football clubs. FFIT is a 12-week program and applies evidence-based behavioral change techniques to improve physical activity and diet in a traditionally male environment. Two powerful forces utilized are the strong bond with the team as a fan (e.g., belonging, identity, loyalty, and validation) and the opportunity to participate in a men-only group. FFIT has been shown to attract men who are at very high risk of disease [15] [16] with good results on weight reduction and a unique outcome with $80 \%$ 
completion rate [17]. FFIT has been shown to be cost-effective, attracting men from across the socioeconomic spectrum [17] and leading to significant long-term weight loss (after 3.5 years) [14].

FFIT has also inspired other sports. Within the Canadian context, Hockey Fans in Training (Hockey FIT) has developed with promising results [18] [19]. In New Zealand, the rugby clubs play an important role and Rugby Fans in Training New Zealand (RUFIT-NZ) delivered via professional rugby clubs demonstrated positive effects on weight and physiologic outcomes, as well as adherence to lifestyle behaviors [20]. Aussie-FIT, the first study in Australia to test an intervention targeting fan health delivered in Australian Football League settings, with 120 overweight/obese men, was carried out in 2018 [21]. In the United Kingdom, evaluation of FFIT for women showed that the program was feasible, acceptable and demonstrated potential as a weight-loss program for women as well [22]. In addition, the FFIT concept has been adapted in other countries and professional sports settings; EuroFIT involves 15 football clubs in four countries. Participation in EuroFIT led to improvements in physical activity, diet, body weight, and biomarkers of cardiometabolic health [23]. Therefore, we developed an intervention, inspired by FFIT, in a Swedish setting delivered through two Swedish professional sports clubs. The intervention is called ViSiT, which in Swedish is the abbreviation for important supporters in training. The aim of this study was to evaluate anthropometry and health changes, program compliance, and the participant's experience/perception of the ViSiT intervention program.

\section{Methods}

\subsection{Study Design and Setting}

This is a feasibility (proof of concept) study delivered in two professional sports clubs (football and ice hockey) in Sweden in 2015-2016. It was designed as a 12-week active phase intervention program followed by a 40-week maintenance phase (less intense intervention). Data collection was performed at baseline, at 12 weeks, and at 52 weeks. The study investigated changes in anthropometry within individuals (e.g., body weight and body composition) and health, program compliance as well as the participant's experiences and perceptions of the program content and delivery. No control group was included in this phase of the intervention design. The study was performed according to the World Medical Association Declaration of Helsinki ethical principles for medical research involving human subjects. This study was approved by the Regional Ethical Review Board in Linköping (Dnr 2016/50-31).

\subsection{Participants}

The target population was overweight and obese male supporters aged 35 - 65 years with a BMI $\geq 28 \mathrm{~kg} / \mathrm{m}^{2}$, the same criteria used in FFIT [17]. Those who were part of another weight-reduction program were excluded. Supporters were 
recruited from two sports clubs located in the County of Östergötland, one football club (IFK Norrköping) and one ice-hockey club (Linköping Hockey $\mathrm{Club}$ ), both in the highest national league with an active supporter culture. The latest population screening (2018) in Östergötland County demonstrated a prevalence of $B M I \geq 28 \mathrm{~kg} / \mathrm{m}^{2}$ of $31 \%$ in men aged $35-50$ years and $45 \%$ in men aged 51 - 65 years (unpublished data from the Public Health Agency of Sweden). Participation was free of charge for the supporters and the sports clubs. Individuals who applied for participation were screened using a registration form, including information about gender, age, height, and weight, to check that they fulfilled the inclusion criteria. Of the 25 individuals enrolled, one did not meet the inclusion criteria and two dropped out before the start of the intervention. Twenty-two individuals were asked to complete the baseline study questionnaire and were invited to the first session of the intervention program. The participants' characteristics are presented in Table 1.

\subsection{Intervention Program}

The ViSiT program was adapted from the concept reported in the FFIT studies [24]. ViSiT is a gender-sensitive program designed and conducted to engage

Table 1. Baseline characteristics of the study participants.

\begin{tabular}{|c|c|c|}
\hline Variable & Unit & Mean (SD) or $n(\%)$ \\
\hline \multirow{3}{*}{ Age group $(n=22)$} & 35 - 44 years & $5(23)$ \\
\hline & $45-54$ years & $8(36)$ \\
\hline & 55 - 64 years & $9(41)$ \\
\hline Body weight $(n=22)$ & $\mathrm{kg}$ & $99.8(9.7)$ \\
\hline $\operatorname{BMI}(n=22)$ & $\mathrm{kg} / \mathrm{m}$ & $31.7(3.2)$ \\
\hline Body fat $(n=22)$ & $\%$ & $33.4(6.9)$ \\
\hline \multirow{2}{*}{ Marital status $(n=21)$} & Married/living together & $17(81)$ \\
\hline & Single & $4(19)$ \\
\hline Born in Sweden $(n=21)$ & Yes & $20(95)$ \\
\hline \multirow{4}{*}{ Education $(n=21)$} & Primary & $3(14)$ \\
\hline & Secondary & $12(57)$ \\
\hline & University & $5(24)$ \\
\hline & Other & $1(5)$ \\
\hline \multirow{3}{*}{ Occupation $(n=21)$} & Working & $18(86)$ \\
\hline & Disability pension & $2(9)$ \\
\hline & Other & $1(5)$ \\
\hline \multirow{4}{*}{ Monthly income (SEK, $n=20$ ) } & $<25,000$ & $4(20)$ \\
\hline & $25,000-30,000$ & $7(35)$ \\
\hline & $30,000-35,000$ & $4(20)$ \\
\hline & $>35,000$ & $5(25)$ \\
\hline
\end{tabular}


overweight and obese male fans to improve their physical activity and support lifestyle changes to lose weight, all delivered in a context that has been found to be appealing and acceptable to men. ViSiT encourages men to lose weight by working with, not against, cultural ideals of masculinity and professional sports clubs in Sweden are a potentially attractive setting to engage men in a weightloss program. ViSiT consists of: 1) an active phase and 2) a maintenance phase. Similar to the FFIT concept [25], the active phase consists of a 12-week groupbased program with one session of 90 minutes each week, including theoretical knowledge and physical exercise (details of the 12-week program are presented in Table 2). The style of delivery of the sessions was participative, involving facilitated discussions and experience sharing among the participants. The active

Table 2. The 12-week ViSiT intervention program.

\begin{tabular}{|c|c|c|}
\hline Week & Activity & Content \\
\hline 1 & $\begin{array}{l}\text { Introduction and } \\
\text { anthropometry }\end{array}$ & $\begin{array}{l}\text { Presentation of participants and program coordinators, } \\
\text { goal-setting, rules for the group work, introduction to } \\
\text { pedometers, short walk }\end{array}$ \\
\hline 2 & Food and drink & $\begin{array}{l}\text { Diet and smart goals, introduction of 3-day food diary, } \\
\text { 15-minute walk }\end{array}$ \\
\hline 3 & Foods and health labeling & $\begin{array}{l}\text { Feedback on food diary and healthy dietary changes, } \\
\text { understanding food packaging labels, } 30 \text { minutes of } \\
\text { physical exercise }\end{array}$ \\
\hline 4 & $\begin{array}{l}\text { Physical activity and } \\
\text { implementation }\end{array}$ & $\begin{array}{l}\text { Importance of physical activity to health and wellbeing, } \\
\text { sedentary behavior, action planning for physical activity, } \\
30 \text { minute of physical exercise }\end{array}$ \\
\hline 5 & Energy in drinks & $\begin{array}{l}\text { Alcohol, other drinks and weight gain, } 30 \text { minutes of } \\
\text { physical exercise }\end{array}$ \\
\hline 6 & Half way anthropometry & $\begin{array}{l}\text { Performance feedback, body weight and composition } \\
\text { measurement, meeting club players and trainers, } 30 \\
\text { minutes of physical exercise }\end{array}$ \\
\hline 7 & Sports psychology & $\begin{array}{l}\text { Feedback on weight loss achieved in the group, sports } \\
\text { psychology (motivation, confidence, mindset, and } \\
\text { behavior), } 30 \text { minutes of physical exercise }\end{array}$ \\
\hline 8 & $\begin{array}{l}\text { Health benefits and } \\
\text { implementation }\end{array}$ & $\begin{array}{l}\text { Health benefits associated with weight loss, role of social } \\
\text { support, } 30 \text { minutes of physical exercise }\end{array}$ \\
\hline 9 & Healthy choices & $\begin{array}{l}\text { Make favorite food healthier, make eating out meals } \\
\text { healthier, } 30 \text { minutes of physical exercise }\end{array}$ \\
\hline 10 & Sports psychology & $\begin{array}{l}\text { Sports psychology (emotions, behavior, relapse, triggers, } \\
\text { locus of control, identity), homework, 3-day food diary, } \\
30 \text { minutes of physical exercise }\end{array}$ \\
\hline 11 & $\begin{array}{l}\text { Recapitulation and future } \\
\text { perspectives }\end{array}$ & $\begin{array}{l}\text { Feedback on food diary, future strategies and goal-setting, } \\
30 \text { minutes of physical exercise }\end{array}$ \\
\hline 12 & Closure and anthropometry & $\begin{array}{l}\text { Performance feedback, questionnaires, body weight and } \\
\text { composition measurement, relapse prevention, ongoing } \\
\text { social support, information and planning for continuation } \\
\text { (e-mail-prompts every } 6 \text { weeks, reunion after } 3 \text { months), } \\
30 \text { minutes of physical exercise }\end{array}$ \\
\hline
\end{tabular}


phase was immediately followed by the maintenance phase, which consisted of six e-mail prompts over 9 months and ended with a group reunion at the club. Representation from the non-profit sport organization (Östergötlands Idrottsförbund) and professionals from the sports clubs, such as the personal trainer and diet advisor, were provided coaching during the 12-week program.

At the first intervention session, all participants received a Fitbit pedometer and a Fitbit web account (Fitbit, Inc., San Francisco, CA, USA) for communication between the pedometer, mobile phone and web account to provide feedback. All participants used a smart phone. Results from the FFIT project showed that self-monitoring using pedometers supported motivation for behavior change [26]. The pedometer was provided during the active phase only, but the web account could be kept afterward. The participants were trained how to use the pedometer with their mobile phone and web account and were provided with additional support if necessary. All participants were encouraged to share Fitbit data with the others for social and motivational support.

\subsection{Measurements}

At baseline, 12 weeks, and 52 weeks, data were collected on body weight, body height, body composition (body fat, muscle mass, body water [\%], bone mass, visceral fat), and the participants completed the study questionnaire. In addition, body weight and body composition were also measured at 6 weeks of the intervention program to provide short-term feedback on progression to participants as motivational support. All equipment was provided by the sports clubs, and the measurements were performed by trained staff members of the clubs in a standardized manner concerning body position and time of day. Body composition was assessed using bioelectrical impedance analysis (Linköping Hockey Club: Inbody 770, Ceritos, CA, USA; IFK Norrköping: Fit3D, Redwood City, CA, USA). Bioelectrical impedance analysis is a valid method to assess body composition in middle-aged men compared with dual energy X-ray absorptiometry, with an individual measurement error for body fat within 5\% - 10\% across the range of body fat in the present study [27].

The study questionnaire included questions about health, motivation, sleep, stress, work capacity, physical activity, dietary intake, tobacco, alcohol, and socioeconomic characteristics.

Attendance was registered at each intervention session to evaluate compliance. In addition to the baseline questionnaire, the questionnaires at 12 weeks and 52 weeks included two additional questions. In the first question, participants' perception of the impact of the program on different health-related aspects was investigated: 1) improved lifestyle, 2) improved health, 3) weight loss, 4) more exercise, 5) improved diet, 6) more energy, 7) better mood, 8) higher motivation for a healthy lifestyle, 9) more knowledge about health, 10) improved self-confidence, 11) got new friends, 12) stronger bond to the club (Figure 1). In the second question, participants' appreciation of the importance of the different 
program components was investigated: 1) group community, 2) connection with the team, 3) theory sessions, 4) exercise sessions, 5) pedometer, 6) weighings, 7) competence of the instructors. Each of the 12 aspects was rated on a scale of $0-5$ ( 0 indicated no impact and 5 very high impact), and each of the seven program components was rated on a scale of 0 - 5 ( 0 indicated not important and 5 very important) (Figure 2).

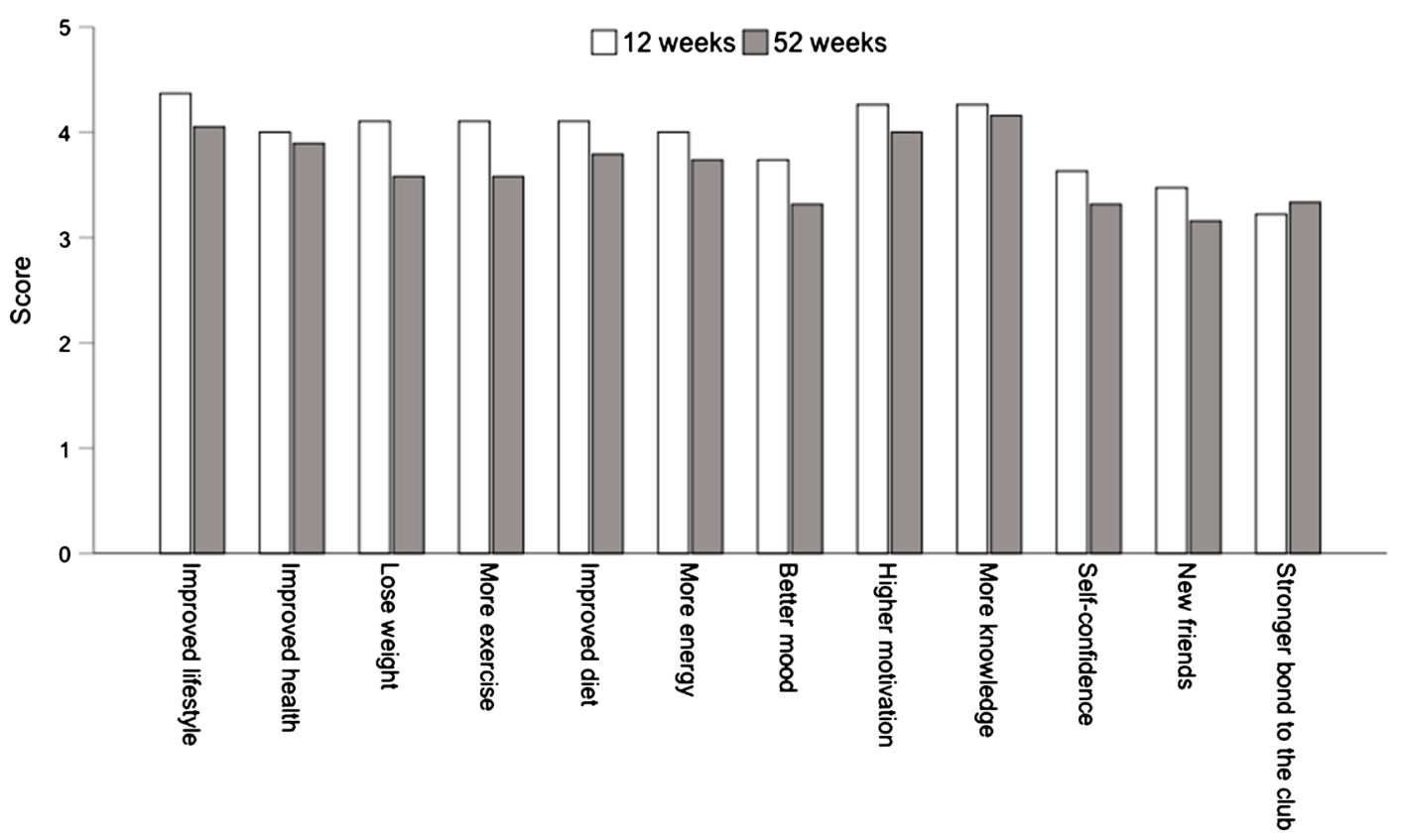

Figure 1. Participants' perception of the impact of the ViSiT program on different aspects related to health. Group mean score, scale from $0=$ no impact to $5=$ very high impact.

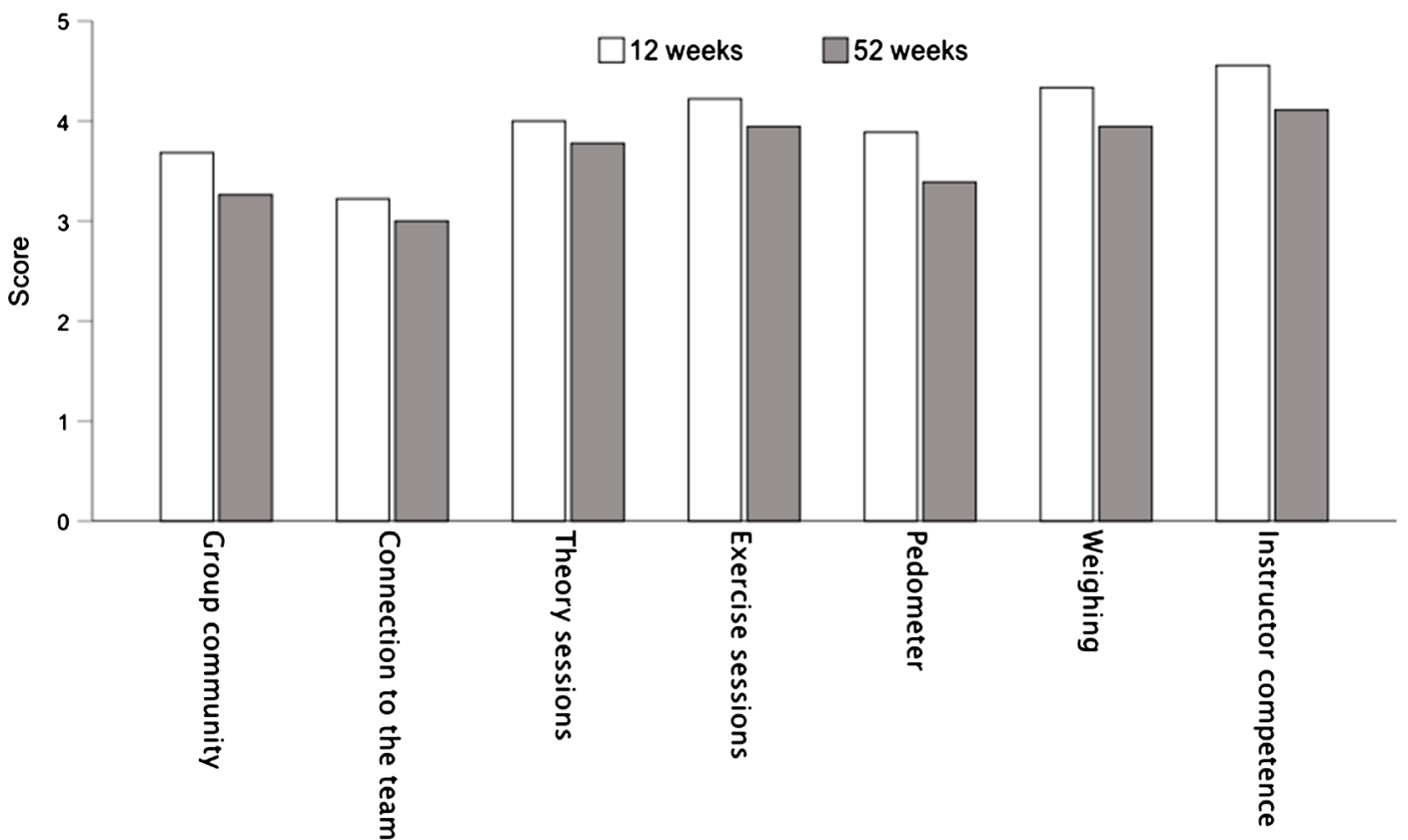

Figure 2. Participants' appreciation of the different program components as being important. Group mean score, scale from $0=$ not important to $5=$ very important. 


\subsection{Statistics}

Means (standard deviation [SD]) and frequencies are presented. A paired Student's $t$ test was used to determine statistically significant differences in anthropometry between baseline and the two follow-ups. All statistics were performed using IBM SPSS Statistics 24.0 (IBM Corp, Armonk, NY, USA). In addition, we investigated the proportion reaching the clinically relevant level of weight reduction of 5\% body weight [10], but also added a higher criterion of $10 \%$ body weight. Further, we also investigated the proportion who were no longer defined as obese (body mass index $<30 \mathrm{~kg} / \mathrm{m}^{2}$ ) or had a BMI $\geq 28 \mathrm{~kg} / \mathrm{m}^{2}$, the inclusion criterion applied here and in the FFIT project [13]. All pairwise comparisons between baseline, 12 weeks, and 52 weeks were also performed with a non-parametric Wilcoxon rank sum test with similar conclusions as the paired Students $t$ test, demonstrating the robustness of Student's $t$ test against non-normality.

\section{Results}

Reductions in body weight and body fat were seen at both follow-ups. The mean (SD) body weight and body fat reductions after 12 weeks were $8.2(4.6) \mathrm{kg}$ and 6.6 (3.6) $\mathrm{kg}$, respectively (Table 3 ). This reduction in body fat corresponds to $4.1 \%(2.3 \%)$ lower proportion of body fat. At 52 weeks, the mean (SD) body weight and body fat reductions were maintained at $6.4(6.7) \mathrm{kg}$ and $4.5(6.5) \mathrm{kg}$, respectively, corresponding to $2.3 \%$ (5.0\%) lower proportion of body fat. Hence, most of the weight reduction was due to loss of body fat.

Of the 22 participants, 18 reached the clinically relevant reduction in body weight of at least $5 \%$ at 12 weeks and $11 \%$ at 52 weeks (Table 4). Five participants reached a higher requirement of at least $10 \%$ reduction in body weight at 12 weeks and 5 at 52 weeks. The weight reductions meant that fewer participants were defined as obese (BMI $\left.\geq 30 \mathrm{~kg} / \mathrm{m}^{2}\right)$ and some reached the level of the initial inclusion criteria (BMI $\geq 28 \mathrm{~kg} / \mathrm{m}^{2}$ ) (Table 4).

Table 3. Anthropometric changes from baseline to 12 weeks and 52 weeks.

\begin{tabular}{|c|c|c|c|c|c|c|c|c|}
\hline \multirow{3}{*}{ Variable } & \multirow{3}{*}{ Unit } & \multicolumn{3}{|c|}{ Values } & \multicolumn{4}{|c|}{ Change } \\
\hline & & Baseline $(n=22)$ & 12 weeks $(n=21)$ & 52 weeks $(n=17)$ & $\Delta 12$ weeks $(n=21)$ & $P$ value ${ }^{*}$ & $\begin{array}{l}\Delta 52 \text { weeks } \\
(n=17)\end{array}$ & $P$ value $^{x}$ \\
\hline & & $\begin{array}{l}\text { Mean (SD), } \\
\text { min - max }\end{array}$ & $\begin{array}{l}\text { Mean (SD), } \\
\min -\max \end{array}$ & $\begin{array}{l}\text { Mean (SD), } \\
\min -\max \end{array}$ & $\begin{array}{l}\text { Mean (SD), } \\
\text { min - max }\end{array}$ & & $\begin{array}{l}\text { Mean (SD), } \\
\text { min - max }\end{array}$ & \\
\hline Body weight & $\mathrm{kg}$ & $\begin{array}{c}99.8(9.7) \\
83.6-124.1\end{array}$ & $\begin{array}{c}92.3(8.5), \\
70.4-108.6\end{array}$ & $\begin{array}{c}92.3(9.6) \\
70.1-105.5\end{array}$ & $\begin{array}{c}-8.2(4.6) \\
-21.0 \text { to }-0.4\end{array}$ & $<0.001$ & $\begin{array}{c}-6.4(6.7) \\
5.1 \text { to }-18.6\end{array}$ & 0.001 \\
\hline BMI & $\mathrm{kg} / \mathrm{m}^{2}$ & $\begin{array}{l}31.7(3.2) \\
28.1-38.2\end{array}$ & $\begin{array}{l}29.3(2.9) \\
24.9-35.8\end{array}$ & $\begin{array}{l}29.4(3.2) \\
24.7-36.8\end{array}$ & $\begin{array}{l}-2.6(1.5) \\
-5.8 \text { to }-0.1\end{array}$ & $<0.001$ & $\begin{array}{l}-2.0(2.2), \\
1.6 \text { to }-7.0\end{array}$ & 0.001 \\
\hline Body fat & $\mathrm{kg}$ & $\begin{array}{l}33.5(8.6) \\
22.1-54.8\end{array}$ & $\begin{array}{l}27.4(7.1), \\
17.5-46.0\end{array}$ & $\begin{array}{l}28.2(8.9), \\
15.0-45.0\end{array}$ & $\begin{array}{l}-6.6(3.6) \\
-15.7-0.0\end{array}$ & $<0.001$ & $\begin{array}{l}-4.5(6.5) \\
7.3 \text { to }-17.0\end{array}$ & 0.011 \\
\hline Body fat & $\%$ & $\begin{array}{l}33.4(6.9) \\
24.3-49.6\end{array}$ & $\begin{array}{l}29.7(6.7) \\
19.0-43.9\end{array}$ & $\begin{array}{c}30.3(8.06) \\
18.0-43.8\end{array}$ & $\begin{array}{l}-4.1(2.3) \\
-8.3-0.1\end{array}$ & $<0.001$ & $\begin{array}{l}-2.3(5.0) \\
7.6 \text { to }-11.6\end{array}$ & 0.030 \\
\hline
\end{tabular}

${ }^{\star}$ Paired student $t$ test. 
Table 4. Degree of weight reduction from baseline to 12 weeks and 52 weeks.

\begin{tabular}{cccc}
\hline Variable & Baseline $(n=22), n(\%)$ & 12 weeks $(n=21), n(\%)$ & 52 weeks $(n=17), n(\%)$ \\
\hline$\geq 5 \%$ weight reduction & - & $18(86)$ & $11(65)$ \\
$\geq 10 \%$ weight reduction & - & $5(24)$ & $5(29)$ \\
$\mathrm{BMI}<30 \mathrm{~kg} / \mathrm{m}^{2}$ & $11(50)$ & $14(67)$ & $12(71)$ \\
$\mathrm{BMI}<28 \mathrm{~kg} / \mathrm{m}^{2}$ & $0(0)$ & $9(43)$ & $6(35)$ \\
\hline
\end{tabular}

Twenty-one of 22 participants completed the 12 -week intervention program. All 22 participants attended at least 6 of 12 sessions, 17 (77\%) attended at least 10 sessions, and 5 attended all 12 sessions. Thirteen participants attended the reunion meeting at the club and 17 attended the final follow-up session at 52 weeks. The participants' perception of the impact of the ViSiT program is presented in Figure 1 and their appreciation of the importance of the different program components is shown in Figure 2. The participants found on average that the program had high impact on all aspects investigated and rated all program components as being important. The scoring was only slightly lower at 52 weeks than at 12 weeks.

\section{Discussion}

The ViSiT intervention program designed specifically to target overweight men showed excellent outcomes concerning participation, attendance, and weight reduction. The results demonstrated clinically relevant weight reduction and most of the weight reduction was in the form of body fat. The intervention also seems to attract participants with different socioeconomic backgrounds, mainly participants with a lower education level and income, increasing the possible public health effect. Hence, this study confirmed the feasibility (proof of concept) of the ViSiT intervention program.

In the FFIT randomized controlled trial, the weight reduction in the intervention group was $5.8 \mathrm{~kg}$ at 12 weeks and $5.6 \mathrm{~kg}$ at 52 weeks [17] [23]. In addition, the proportion reaching at least $5 \%$ weight reduction was $47 \%$ and $39 \%$, respectively, and the proportion achieving a BMI $<30 \mathrm{~kg} / \mathrm{m}^{2}$ was $26 \%$ and $26 \%$, respectively. In the FFIT feasibility study, with similar weight reduction as in the main study, the proportion of body fat was assessed with bioelectrical impedance analysis and reported to be reduced by only $1.1 \%$ at 12 weeks and by $1.4 \%$ at 52 weeks [28]. This study also presented the proportion reaching at least $10 \%$ weight reduction as $2 \%$ at 12 weeks and $8 \%$ at 52 weeks. Therefore, the reduction in body weight and body fat in the present study indicates that the ViSiT program is a promising concept targeting behavior change in overweight men at risk of cardiometabolic disease, especially considering the supporter culture in Sweden is not as strong as it is in Scotland.

Weight reduction in group-based diet and/or physical activity interventions ranges between $0.4 \mathrm{~kg}$ and $9.7 \mathrm{~kg}$ with a mean of $4.2 \mathrm{~kg}$ at 52 weeks [9]. There 
are few weight-loss interventions involving men only, and among those targeting diet and/or physical activity changes, the FFIT study has been the most effective [10]. Hence, there is an opportunity for Swedish football and ice-hockey clubs to contribute to clinically relevant weight reduction in their male members, and according to the analysis performed in the FFIT study, this intervention format is inexpensive and cost-effective [17].

Group-based interventions produce important weight reductions and once participants are engaged, they seem to remain committed, indicated by the high retention rate [10]. In the FFIT study, the proportion of participants remaining in the intervention after 12 weeks and 52 weeks was about 90\% [17]. Further, about $80 \%$ attended at least 6 of 12 sessions in the active phase.

In the development of the FFIT intervention, the participants were interviewed and asked to provide feedback on the different intervention components and make suggestions for development [24]. Some said they appreciated the camaraderie the most followed by the inclusion of the physical activity sessions (although they would have liked more football), the lifestyle education and the attitude of the coaches. In the ViSiT study, the participants appreciated all aspects of the program as being important. Moreover, this insight was stable over time because the scoring was only slightly lower at 52 weeks than at 12 weeks. The participants appreciated the lecturers the most, followed by the immediate feedback provided by weighing, the physical training sessions as well as the theoretical knowledge provided. Hence, there were some differences in the appreciation of the different components of the intervention between the studies, although similarities also occurred.

The participants experienced the ViSiT intervention as having impact on numerous aspects related to health, such as improved lifestyle with more exercise and a healthy diet, weight reduction, more knowledge, and the feeling of more energy and motivation. The FFIT study reported an increase in self-esteem and quality of life [17]. Hence, the concept of placing lifestyle interventions including diet and physical activity in professional sports clubs could have the potential to attract and motivate Swedish overweight men to consider required behavior changes.

The FFIT concept has spread across the world via rugby (RUFIT-NZ, New Zealand) [20], football (Aussie-FIT, Australia) [21] hockey (Hockey FIT, Canada) [18] [19] and in Europe via EuroFIT [23]. Thus, this type of intervention needs refinement to fit into different contexts. For further scaling up in Sweden, the next step would be to perform a large randomized controlled study involving more sports clubs. Previous research has shown that the perception that an intervention has been successful for other men is a key factor in motivation to participate in an intervention [29]. Thereby, the recruitment of participants might be easier the longer the intervention has been in place. If the same weight reduction as in the present study could be achieved, as is indicated from the similar outcomes of the FFIT feasibility study and the FFIT main study, there would be 
a large impact on public health because more than $50 \%$ of Swedish men are overweight.

\section{Strengths and Limitations}

This study was built on the experience from the FFIT study and its study protocol. Our focus was mainly to validate the method itself and to gather more knowledge about the concept implemented in our Swedish context, therefore our study lacks a control group and the sample size is relatively small. We have made some changes from the original concept and added the measurement of body composition. Although this was thought to improve the results of the intervention, the lack of fidelity to the original concept makes it harder to compare our results with results from previous studies. Despite these differences, the effect of the intervention seems to be the same in both clubs.

\section{Conclusion}

The ViSiT feasibility study of a healthy living intervention program in the regimen of elite football and ice-hockey clubs demonstrated a successful retention rate and clinically relevant weight reduction in Swedish overweight men. The maintenance of reduced body weight, as well as positive perception/experience after 1 year, indicate a long-term effect of the ViSiT concept.

\section{Data Availability}

The data supporting the conclusions of this article are available from the authors.

\section{Ethical Approval}

The Regional Ethical Review Board in Linköping (Dnr 2016/50-31) approved this study.

\section{Consent}

All the participants gave their consent to participate in the project and the evaluation when they registered and completed the registration form.

\section{Authors' Contributions}

Design of the intervention: ML, KÅ; Study concept and design: ML and DA; Analysis and interpretation of data: NK, KÅ, JS, PD, DA, ML. All authors participated in the preparation of the manuscript, provided critical revisions, and agreed to the final version of the paper before submission.

\section{Acknowledgements}

Many thanks to Lolita Blad, health and sport advisor at the Regional Sport Confederation for taking part in designing the educational material and for your catching enthusiasm for the intervention. Thanks to the club director, Anders Mäki, Linköpings Hockey Club, and sales and marketing director, Mathias 
Lövenfors, IFK Norrköping, for being willing to try ViSiT and for good cooperation and enthusiasm regarding the project.

\section{Conflicts of Interest}

The authors declare no conflicts of interest regarding the publication of this paper.

\section{References}

[1] World Health Organization (2018) Obesity and Overweight Fact Sheet, World Health Organization.

https://www.who.int/news-room/fact-sheets/detail/obesity-and-overweight

[2] McKinsey Global Institute (2014) Overcoming Obesity: An Initial Economic Analysis. McKinsey Global Institute.

[3] Di Angelantonio, E., Bhupathiraju, S.N., Wormser, D., et al. (2016) Body-Mass Index and All-Cause Mortality: Individual-Participant-Data Meta-Analysis of 239 Prospective Studies in Four Continents. The Lancet, 388, 776-786.

[4] The Public Health Agency of Sweden (2018) Overweight and Obesity. https://www.folkhalsomyndigheten.se/folkhalsorapportering-statistik/folkhalsans-u tveckling/halsa/overvikt-och-fetma/

[5] Ma, C., Avenell, A., Bolland, M., et al. (2017) Effects of Weight Loss Interventions for Adults Who Are Obese on Mortality, Cardiovascular Disease, and Cancer: Systematic Review and Meta-Analysis. British Medical Journal, 359, j4849. https://doi.org/10.1136/bmj.j4849

[6] Ek, S. (2013) Gender Differences in Health Information Behaviour: A Finnish Population-Based Survey. Health Promotion International, 30, 736-745.

https://doi.org/10.1093/heapro/dat063

[7] Pagoto, S.L., Schneider, K.L., Oleski, J.L., Luciani, J.M., Bodenlos, J.S. and Whited, M.C. (2012) Male Inclusion in Randomized Controlled Trials of Lifestyle Weight Loss Interventions. Obesity, 20, 1234-1239. https://doi.org/10.1038/oby.2011.140

[8] Robertson, C., Archibald, D., Avenell, A., et al. (2014) Systematic Reviews of and Integrated Report on the Quantitative, Qualitative and Economic Evidence Base for the Management of Obesity in Men. Health Technology Assessment, 18, v-vi, xxiii-xxix, 1-424. https://doi.org/10.3310/hta18350

[9] Borek, A.J., Abraham, C., Greaves, C.J. and Tarrant, M. (2018) Group-Based Diet and Physical Activity Weight-Loss Interventions: A Systematic Review and MetaAnalysis of Randomised Controlled Trials. Applied Psychology: Health and WellBeing, 10, 62-86. https://doi.org/10.1111/aphw.12121

[10] Robertson, C., Avenell, A., Stewart, F., et al. (2017) Clinical Effectiveness of Weight Loss and Weight Maintenance Interventions for Men: A Systematic Review of MenOnly Randomized Controlled Trials (The ROMEO Project). American Journal of Men's Health, 11, 1096-1123. https://doi.org/10.1177/1557988315587550

[11] Jensen, M.D., Ryan, D.H., Apovian, M., et al. (2014) 2013 AHA/ACC/TOS Guideline for the Management of Overweight and Obesity in Adults: HHS Public Access Preamble and Transition to ACC/AHA Guidelines to Reduce Cardiovascular Risk. Circulation, 129, 102-138.

[12] Drygas, W., Ruszkowska, J., Philpott, M., et al. (2013) Good Practices and Health Policy Analysis in European Sports Stadia: Results from the "Healthy Stadia" Project. Health Promotion International, 28, 157-165. 
https://doi.org/10.1093/heapro/dar088

[13] Pringle, A., Zwolinsky, S., McKenna, J., Daly-Smith, A., Robertson, S. and White, A. (2013) Delivering Men's Health Interventions in English Premier League Football Clubs: Key Design Characteristics. Public Health, 127, 716-726. https://doi.org/10.1016/j.puhe.2013.04.011

[14] Gray, C.M., Wyke, S., Zhang, R., et al. (2018) Long-Term Weight Loss Following a Randomised Controlled Trial of a Weight Management Programme for Men Delivered through Professional Football Clubs: The Football Fans in Training Followup Study. Public Health Research, 6. https://doi.org/10.3310/phr06090

[15] Hunt, K., Gray, C.M., Maclean, A., Smillie, S., Bunn, C. and Wyke, S. (2014) Do Weight Management Programmes Delivered at Professional Football Clubs Attract and Engage High Risk Men? A Mixed-Methods Study. BMC Public Health, 14, 50. https://doi.org/10.1186/1471-2458-14-50

[16] Bunn, C., Wyke, S., Gray, C.M., Maclean, A. and Hunt, K. (2016) "Coz Football Is What We All Have": Masculinities, Practice, Performance and Effervescence in a Gender-Sensitised Weight-Loss and Healthy Living Programme for Men. Sociology of Health \& Illness, 38, 812-828. https://doi.org/10.1111/1467-9566.12402

[17] Hunt, K., Wyke, S., Gray, C.M., et al. (2014) A Gender-Sensitised Weight Loss and Healthy Living Programme for Overweight and Obese Men Delivered by Scottish Premier League Football Clubs (FFIT): A Pragmatic Randomised Controlled Trial. The Lancet, 383, 1211-1221. https://doi.org/10.1016/S0140-6736(13)62420-4

[18] Petrella, R.J., Gill, D.P., Zou, G., et al. (2017) Hockey Fans in Training: A Pilot Pragmatic Randomized Controlled Trial. Medicine \& Science in Sports \& Exercise, 49, 2506-2516. https://doi.org/10.1249/MSS.0000000000001380

[19] Blunt, W., Gill, D.P., Sibbald, S.L., et al. (2017) Optimization of the Hockey Fans in Training (Hockey FIT) Weight Loss and Healthy Lifestyle Program for Male Hockey Fans. BMC Public Health, 17, 916. https://doi.org/10.1186/s12889-017-4926-Z

[20] Maddison, R., Hargreaves, E.A., Wyke, S., et al. (2019) Rugby Fans in Training New Zealand (RUFIT-NZ): A Pilot Randomized Controlled Trial of a Healthy Lifestyle Program for Overweight Men Delivered through Professional Rugby Clubs in New Zealand. BMC Public Health, 19, 166. https://doi.org/10.1186/s12889-019-6472-3

[21] Quested, E., Kwasnicka, D., Thøgersen-Ntoumani, C., et al. (2018) Protocol for a Gender-Sensitised Weight Loss and Healthy Living Programme for Overweight and Obese Men Delivered in Australian Football League Settings (Aussie-FIT): A Feasibility and Pilot Randomised Controlled Trial. BMJ Open, 8, e022663. https://doi.org/10.1136/bmjopen-2018-022663

[22] Bunn, C., Donnachie, C., Wyke, S., et al. (2018) Can Professional Football Clubs Deliver a Weight Management Programme for Women: A Feasibility Study. BMC Public Health, 18, 1330. https://doi.org/10.1186/s12889-018-6255-2

[23] Wyke, S., Bunn, C., Andersen, E., et al. (2019) The Effect of a Programme to Improve Men's Sedentary Time and Physical Activity: The European Fans in Training (EuroFIT) Randomised Controlled Trial. PLoS Medicine, 16, e1002736.

[24] Gray, C.M., Hunt, K., Mutrie, N., et al. (2013) Football Fans in Training: The Development and Optimization of an Intervention Delivered through Professional Sports Clubs to Help Men Lose Weight, Become More Active and Adopt Healthier Eating Habits. BMC Public Health, 13, 232. https://doi.org/10.1186/1471-2458-13-232

[25] Wyke, S., Hunt, K., Gray, C.M., et al. (2015) Football Fans in Training (FFIT): A Randomised Controlled Trial of a Gender-Sensitised Weight Loss and Healthy Liv- 
ing Programme for Men-End of Study Report. Public Health Research, 3, 1-130. https://doi.org/10.3310/phr03020

[26] Donnachie, C., Wyke, S., Mutrie, N. and Hunt, K. (2017) "It's Like a Personal Motivator that You Carried around Wi' You": Utilising Self-Determination Theory to Understand Men's Experiences of Using Pedometers to Increase Physical Activity in a Weight Management Programme. International Journal of Behavioral Nutrition and Physical Activity, 14, 61. https://doi.org/10.1186/s12966-017-0505-z

[27] Ling, C.H.Y., de Craen, A.J., Slagboom, P.E., et al. (2011) Accuracy of Direct Segmental Multi-Frequency Bioimpedance Analysis in the Assessment of Total Body and Segmental Body Composition in Middle-Aged Adult Population. Clinical Nutrition, 30, 610-615. https://doi.org/10.1016/j.clnu.2011.04.001

[28] Gray, C.M., Hunt, K., Mutrie, N., Anderson, A.S., Treweek, S. and Wyke, S. (2013) Weight Management for Overweight and Obese Men Delivered through Professional Football Clubs: A Pilot Randomized Trial. International Journal of Behavioral Nutrition and Physical Activity, 10, 121. https://doi.org/10.1186/1479-5868-10-121

[29] Leishman, J. (2007) Working with Men in Groups-Experience from a Weight Management Program in Scotland. CRC Press, London.

\section{Abbreviations}

BMI: $\quad$ Body mass index

FFIT: Football Fans in Training

ViSiT: Viktiga Supportrar i Träning (Swedish for important supporters in training) 